\title{
Níveis de lisina digestível em dietas para suínos machos castrados dos 60 aos 100 dias de idade
}

\section{Gustavo Gattás ${ }^{1}$, Francisco Carlos de Oliveira Silva ${ }^{2}$, Fellipe Freitas Barbosa ${ }^{3}$, Juarez Lopes Donzele $^{4}$, Aloízio Soares Ferreira ${ }^{4}$, Rita Flávia Miranda de Oliveira ${ }^{4}$}

\author{
1 Rio Branco Alimentos. \\ 2 EPAMIG. \\ ${ }^{3}$ Agroceres Nutrição Animal. \\ ${ }^{4}$ Departamento de Zootecnia, UFV.
}

RESUMO - Para avaliar o efeito de níveis de lisina digestível sobre o desempenho e as características de carcaça de suínos

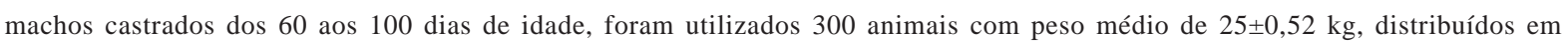
delineamento experimental de blocos ao acaso, com 5 tratamentos $(0,65 ; 0,75 ; 0,85 ; 0,95$ e 1,05\% de lisina digestível), 5 repetições e 12 animais por unidade experimental. Não houve efeito dos níveis de lisina digestível sobre o consumo médio diário de ração. O consumo de lisina digestível aumentou de forma linear com o aumento desse aminoácido na ração. O ganho de peso médio diário aumentou e a conversão alimentar melhorou de forma quadrática com o aumento dos níveis de lisina digestível da ração. Não foi observado efeito dos níveis de lisina digestível sobre a espessura de toucinho dos animais, entretanto, o rendimento de carcaça e a quantidade de carne aumentaram de forma quadrática com o aumento dos níveis de lisina digestível. Os níveis de 0,96 e 0,92\% de lisina digestível, correspondentes aos consumos estimados de 18,69 e 17,69 g/dia, proporcionam os melhores resultados de ganho de peso e conversão alimentar, enquanto os níveis de 0,89 e 0,90\%, correspondentes aos consumos estimados de 17,28 e 17,52 g/dia, propiciam os melhores resultados de rendimento e quantidade de carne na carcaça de suínos machos castrados dos 60 aos 100 dias de idade.

Palavras-chave: aminoácido digestível, carcaça, carne magra, espessura de toucinho, fase de crescimento

\section{Dietary digestible lysine levels in diets for barrows from 60 to 100 days of age}

\begin{abstract}
In order to evaluate digestible lysine levels on the performance and carcass traits of castrated male pigs from 60 to 100 days of age, 300 barrows with initial weight of $25.0 \pm 0.52 \mathrm{~kg}$ were allotted in a completely randomized block design with five treatments $(0.65,0.75,0.85,0.95$, and $1.05 \%$ digestible lysine levels), five replicates, and 12 pigs per experimental unit. There was no effect of digestible lysine levels on average daily feed intake. The average daily gain increased and feed conversion improved quadratically with increasing dietary digestible lysine levels. There was no effect of the digestible lysine levels on pig backfat thickness; however the carcass yield and quantity of meat increased quadratically with increasing digestible lysine levels in the diets. The levels of 0.96 and $0.92 \%$ digestible lysine, corresponding to the estimated intakes of 18.69 and $17.69 \mathrm{~g} /$ day provide the best results of weight gain and feed conversion, while levels of 0.89 and $0.90 \%$, corresponding to the estimated intakes of 17.28 and $17.52 \mathrm{~g}$ /day, provide the best results of yield and quantity of meat in the carcass of barrows from 60 to 100 days of age.
\end{abstract}

Key Words: amino acid digestibility, backfat thickness, carcass, growth phase, lean

\section{Introdução}

A determinação mais precisa das exigências nutricionais dos suínos utilizando-se o conceito de proteína ideal e a avaliação da qualidade de alimentos têm otimizado a produção de rações por permitir adequado suprimento de aminoácidos, bem como de outros nutrientes essenciais. A realização de pesquisas em nutrição de suínos envolvendo aminoácidos industriais tem sido justificada pela importância nutricional dos aminoácidos para síntese de proteínas corporais e formulação de rações utilizando-se o conceito de proteína ideal.

Em estudos com aminoácidos, tem-se a lisina como referência nutricional, por ser um aminoácido estritamente essencial, não sintetizado pelos suínos e por ser o primeiro aminoácido limitante em rações práticas à base de milho e farelo de soja. A lisina também tem sido considerada o nutriente mais importante para deposição de carne magra 
na carcaça de suínos em crescimento. Isto se deve à sua constância na proteína corporal e sua destinação metabólica preferencial para a deposição de tecido muscular (Kessler, 1998).

Os suínos possuem diferentes potenciais para deposição de carne e gordura na carcaça, que podem variar em função da genética, idade e sexo dos animais. Suínos de alto potencial genético para deposição de carne têm suas exigências em aminoácidos, principalmente lisina, aumentadas, devido à constância desse aminoácido na proteína corporal e sua destinação metabólica preferencial para deposição de tecido muscular. Suínos mais jovens, por depositarem proporcionalmente mais tecido muscular que gordura e apresentar menor consumo voluntário, têm maior exigência, em percentuais de aminoácidos, que suínos mais velhos. Entretanto, quantitativamente os suínos mais velhos necessitam de maiores quantidades de aminoácidos em comparação aos mais jovens (Arouca et al., 2004).

Por outro lado, suínos machos castrados e fêmeas diferem quanto ao padrão de deposição de carne e gordura na carcaça. As fêmeas depositam de mais proteína em comparação aos machos castrados (Quiniou et al., 1999), entretanto suínos machos castrados consomem maiores quantidades de ração e esse maior consumo voluntário pode proporcionar ingestão de energia superior à sua exigência e esse excesso de energia é depositado como gordura (Arouca et al., 2004). Desse modo, grupos sexuais de suínos (machos castrados e fêmeas) podem apresentar diferenças nas necessidades nutricionais, em razão do padrão de consumo. Assim, o objetivo neste estudo foi avaliar, utilizando-se o conceito de proteína ideal, o efeito de níveis de lisina digestível sobre o desempenho e as características de carcaça de suínos machos castrados dos 60 aos 100 dias de idade.

\section{Material e Métodos}

O experimento foi conduzido na Granja Escola da Universidade de Rio Verde (FESURV), na cidade de Rio Verde, Goiás, no período de março a maio de 2006. Foram utilizados 300 suínos machos castrados híbridos de linhagem comercial com alto potencial genético para deposição de carne na carcaça, com peso inicial de $25 \pm 0,52 \mathrm{~kg}$ e 60 dias de idade, distribuídos em delineamento experimental de blocos aos acaso, com 5 tratamentos (níveis de lisina digestível na ração), 5 repetições, com 12 animais por unidade experimental, considerando o peso inicial como critério para distribuição dos animais dentro das repetições.

Os tratamentos consistiram de diferentes níveis de lisina digestível obtidos a partir da inclusão de níveis crescentes de L-lisina $\mathrm{HCl}(78,8 \%)$, resultando em rações experimentais com: 0,$65 ; 0,75 ; 0,85 ; 0,95$; ou $1,05 \%$ de lisina digestível.

Os animais foram alojados em baias coletivas com comedouro linear com 2,0 m comprimento, 0,25 m largura e $0,15 \mathrm{~m}$ de altura, possibilitando de seis animais simultaneamente e bebedouros tipo chupeta sendo um do tipo pendular por baia, em galpão de alvenaria, com piso compacto dotado de lâmina d'água e cobertura com telha metálica.

A ventilação e a temperatura do ambiente foram controladas por abertura e fechamento de cortinas. O registro diário da temperatura foi realizado utilizando-se termômetros de máxima e mínima, instalados em uma baia vazia a uma altura correspondente à meia-altura do corpo dos animais.

As rações experimentais foram formuladas à base de milho e farelo de soja e suplementadas com minerais e vitaminas para atender às exigências dos animais de acordo com Rostagno et al. (2005), exceto em relação à lisina (Tabela 1). A exigência do quarto aminoácido limitante (triptofano) foi atendida por meio da variação das proporções de milho e farelo de soja. Em cada nível de lisina estudado, foi verificada a relação entre os demais aminoácidos essenciais e a lisina digestível, a fim de assegurar que nenhum outro aminoácido ficasse limitante na ração. Na avaliação das relações aminoacídicas das rações, foram utilizadas as relações preconizadas por Rostagno et al. (2005) na proteína ideal para suínos na fase inicial.

Ração e água foram fornecidas à vontade aos animais, sendo que a digestibilidade dos aminoácidos industriais adicionados à ração foi considerada $100 \%$.

As rações foram pesadas diariamente e as sobras de ração coletadas, também diariamente, armazenadas e pesadas no final do período experimental para determinação do consumo diário de ração. Os animais foram pesados no início e ao final do período experimental, que teve duração de 40 dias, para determinação do ganho de peso diário. A conversão alimentar foi obtida dividindo-se o consumo de ração pelo ganho de peso.

Ao final do experimento, os animais foram submetidos a um jejum de 12 horas. o animal de peso mais próximo ao peso médio de cada repetição foi novamente pesado e transportado até o abatedouro, onde foi abatido conforme procedimentos da indústria, para verificação de características de carcaça. As características de carcaça avaliadas foram rendimento de carcaça, quantidade de carne e espessura de toucinho.

As análises estatísticas das variáveis de desempenho (ganho de peso, consumo de ração e conversão alimentar) 
Tabela 1 - Composições centesimal e nutricional calculadas das rações experimentais

\begin{tabular}{|c|c|c|c|c|c|}
\hline \multirow[t]{2}{*}{ Ingrediente } & \multicolumn{5}{|c|}{ Nível de lisina digestível (\%) } \\
\hline & 0,65 & 0,75 & 0,85 & 0,95 & 1,05 \\
\hline Milho & 73,33 & 73,20 & 72,01 & 69,02 & 65,94 \\
\hline Óleo de soja degomado & 2,35 & 2,35 & 2,35 & 2,35 & 2,35 \\
\hline Fosfato bicálcico & 1,95 & 1,95 & 1,95 & 1,95 & 1,95 \\
\hline Calcário calcítico & 0,25 & 0,25 & 0,25 & 0,25 & 0,25 \\
\hline DL-metionina & - & - & 0,03 & 0,06 & 0,09 \\
\hline L-treonina $(98,5 \%)$ & - & - & 0,06 & 0,08 & 0,10 \\
\hline Premix mineral vitamínico ${ }^{1}$ & 0,60 & 0,60 & 0,60 & 0,60 & 0,60 \\
\hline Total & 100,00 & 100,00 & 100,00 & 100,00 & 100,00 \\
\hline \multicolumn{6}{|l|}{ Composição nutricional calculada ${ }^{2}$} \\
\hline Energia digestível (kcal/kg) & 3.476 & 3.478 & 3.479 & 3.479 & 3.479 \\
\hline Metionina + cistina digestível $(\%)^{3}$ & 0,44 & 0,44 & 0,48 & 0,53 & 0,59 \\
\hline Metionina digestível $(\%)^{3}$ & 0,22 & 0,22 & 0,25 & 0,29 & 0,34 \\
\hline Treonina digestível $(\%)^{3}$ & 0,47 & 0,47 & 0,54 & 0,60 & 0,66 \\
\hline Triptofano digestível $(\%)^{3}$ & 0,14 & 0,14 & 0,15 & 0,16 & 0,18 \\
\hline Valina digestível $(\%)^{3}$ & 0,61 & 0,61 & 0,63 & 0,67 & 0,72 \\
\hline Arginina digestível $(\%)^{3}$ & 0,92 & 0,92 & 0,95 & 1,03 & 1,11 \\
\hline Cálcio (\%) & 0,64 & 0,64 & 0,64 & 0,64 & 0,65 \\
\hline Fósforo total (\%) & 0,56 & 0,56 & 0,56 & 0,57 & 0,59 \\
\hline Fósforo disponível (\%) & 0,43 & 0,43 & 0,43 & 0,43 & 0,43 \\
\hline Sódio (\%) & 0,20 & 0,20 & 0,20 & 0,20 & 0,20 \\
\hline
\end{tabular}

e das características de carcaça (rendimento de carcaça, quantidade de carne e espessura de toucinho) foram realizadas utilizando-se o programa computacional SAEG (Sistema de Análise Estatística e Genética, versão 9.1).

As estimativas dos melhores níveis de lisina digestível foram determinadas com base nos resultados de desempenho e características de carcaça por meio de análises de regressão linear, quadrática e/ou pelo modelo descontínuo Linear Response Plateau (LRP), conforme o melhor ajustamento obtido para cada variável estudada.

\section{Resultados e Discussão}

As médias das temperaturas mínima e máxima no interior do galpão durante o período experimental mantiveram-se, respectivamente, entre $16,9 \pm 4,32{ }^{\circ} \mathrm{C}$ e $28,6 \pm 2,97{ }^{\circ} \mathrm{C}$. Considerando-se que a faixa ideal de temperatura para suínos na fase de crescimento sugerida por Coffey et al. (2000) está entre $16 \mathrm{e} 24^{\circ} \mathrm{C}$, pode-se inferir que provavelmente os animais foram submetidos por alguns períodos durante o experimento a estresse por calor, o que pode ter afetado o desempenho dos animais.
O consumo diário de ração não foi influenciado $(\mathrm{P} \geq 0,10)$ pelos níveis de lisina da ração (Tabela 2). Resultados semelhantes foram observados por Abreu (2005), que, avaliando níveis de lisina digestível entre 0,80 a 1,10\% para suínos machos castrados dos 30 aos $60 \mathrm{~kg}$, não constatou efeito sobre o consumo diário de ração dos animais. Da mesma forma, Donzele et al. (1994) e Haese et al. (2011) não notaram efeito dos níveis de lisina sobre o consumo diário de ração dos suínos.

De forma contrária, Fontes et al. (2005) avaliaram níveis de lisina digestível entre 0,712 e 1,068\% e verificaram efeito quadrático sobre o consumo diário de ração pelos suínos de alto potencial genético na fase dos 30 aos $60 \mathrm{~kg}$. Salienta-se, entretanto, que, no estudo de Fontes et al. (2005), o aumento dos níveis de lisina não foi acompanhado por aumentos nas concentrações dos demais aminoácidos essenciais, o que pode ter levado a desbalanço de aminoácidos e explicar em parte, a diferença dos resultados em relação aos deste estudo.

Assim, o desbalanço de aminoácidos na ração pode ter como sintoma característico a diminuição do consumo voluntário de ração pelos animais (D’Mello, 1993). Dessa 
Tabela 2 - Desempenho e consumo de lisina de suínos machos castrados recebendo diferentes níveis de lisina na ração na fase dos 60 aos 100 dias de idade

\begin{tabular}{lccccc}
\hline Parâmetro & \multicolumn{3}{c}{ Nível de lisina digestível (\%) } & \multicolumn{2}{c}{ CV (\%) } \\
\cline { 2 - 5 } & 0,65 & 0,75 & 0,85 & 0,95 & 1,05 \\
\hline Peso médio inicial (kg) & 25,15 & 25,15 & 25,15 & 25,13 & 25,18 \\
Peso médio final (kg) & 60,27 & 59,91 & 61,48 & 62,55 & 61,16 \\
Consumo de ração diário (g) & 1978 & 1894 & 1960 & 1958 & 1946 \\
Consumo de lisina digestível (g/dia) ${ }^{1}$ & 12,86 & 14,21 & 16,67 & 18,60 & 20,43 \\
Ganho de peso diário (g) & 878 & 869 & 908 & 935 & 8,34 \\
Conversão alimentar (g/g) & 2,25 & 2,18 & 2,16 & 2,09 & 3,12 \\
\hline
\end{tabular}

${ }^{1}$ Efeito linear $(\mathrm{P} \leq 0,01)$.

2,3 Efeito quadrático $(\mathrm{P} \leq 0,05)$ e $(\mathrm{P}=0,067)$, respectivamente

forma, o fato de as rações experimentais terem sido formuladas de forma que as concentrações dos aminoácidos essenciais mantivessem relações com a lisina, de acordo com os conceitos de proteína ideal, justifica, em parte, a similaridade dos dados de consumo diário de ração entre os níveis de lisina digestível.

Os níveis de lisina da ração influenciaram $(\mathrm{P} \leq 0,01)$ o consumo de lisina digestível, que aumentou de forma linear, segundo equação $\hat{Y}=-0,2537+19,6974 X\left(R^{2}=0,95\right)$, corroborando os resultados obtidos por Souza (1997) e Abreu et al. (2007), que também observaram aumento linear do consumo de lisina digestível com o acréscimo no nível de lisina das rações.

Como não foi observada variação significativa do consumo diário de ração e as concentrações de lisina nas rações foram crescentes, pode-se inferir que o aumento do consumo diário de lisina esteve diretamente relacionado aos níveis de lisina das rações.

Os tratamentos influenciaram $(\mathrm{P} \leq 0,05)$ o ganho de peso diário, que aumentou de forma quadrática até o nível estimado de 0,96\% de lisina digestível (Tabela 2; Figura 1), correspondente a um consumo de lisina de 18,69 g/dia. Resultado semelhante foi observado por Warnants et al. (2003), que, avaliando níveis de lisina digestível para suínos machos castrados híbridos dos 30 aos 49 kg, constataram que o ganho de peso dos animais foi influenciado de forma

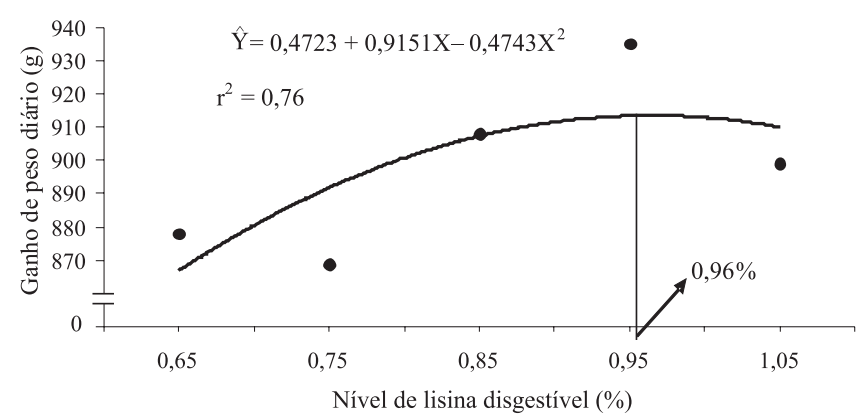

Figura 1 - Efeito do nível de lisina sobre o ganho de peso diário de suínos machos castrados dos 60 aos 100 dias de idade. quadrática pelos níveis de lisina, porém o nível estimado de lisina digestível que proporcionou a melhor resposta foi o de 1,09\%. Por outro lado, Souza (1997), avaliando níveis entre 0,580 e 0,830\% de lisina digestível para suínos machos castrados dos 30 aos 60 kg com média capacidade genética para deposição de tecido muscular, verificou efeito linear crescente sobre o ganho de peso diário dos animais. Entretanto, o nível de lisina que proporcionou o melhor resultado em valor absoluto foi o de 0,780\% de lisina. Em contrapartida, Donzele et al. (1994), Abreu et al. (2007) e Haese et al. (2011) não observaram efeito dos níveis de lisina sobre o ganho de peso diário dos animais.

Abreu et al. (2007), embora não tenham verificado efeitos significativos dos níveis de lisina sobre o ganho de peso diário, notaram aumento de $8,7 \%$ em valor absoluto para este parâmetro quando o consumo diário de lisina aumentou de 15,81 para 20,64 g/dia de lisina digestível, referente ao um aumento de 0,80 a $1,00 \%$ nos níveis de lisina na ração.

O valor de $0,96 \%$ de lisina digestível, correspondente a um consumo de lisina digestível de 18,66 g/dia, que proporcionou os melhores resultados para o ganho de peso diário foi inferior aos valores verificados por Abreu et al. (2007), de 20,64 g/dia de lisina digestível. Entretanto, foi superior ao observado por Souza (1997), de 16,87 g/dia de lisina digestível (18,85 g/dia de lisina total). Esse resultado corrobora o relato de Friesen et al. (1994) de que genótipos caracterizados como de alto potencial para ganho de tecido muscular tem maior exigência de lisina se comparados a genótipos com médio potencial para deposição de tecido muscular.

A diferença de ganho de peso diário entre esses trabalhos pode estar relacionada aos grupos genéticos utilizados, ao sistema de alimentação (Stahly et al., 1991), ao perfil de aminoácidos da dieta, ao estado de saúde e ao sexo dos animais (Santos et al., 2011).

O aumento dos níveis de lisina digestível da ração influenciou $(\mathrm{P}=0,067)$ de forma quadrática a conversão alimentar dos machos castrados, que melhorou até o nível 
estimado de 0,92\% de lisina digestível (Tabela 2; Figura 2), que corresponde a um consumo diário de lisina de 17,91 g/dia. Do mesmo modo, Souza (1997) e Abreu et al. (2007) também verificaram efeitos positivos dos níveis de lisina sobre a conversão alimentar dos suínos, entretanto constataram melhora linear com o aumento dos níveis de lisina na ração. Em contrapartida, Haese et al. (2011) avaliaram níveis de lisina para suínos machos castrados na fase inicial de crescimento e não notaram efeito sobre a conversão alimentar dos animais.

Odecréscimo na eficiência de utilização da ração noúltimo nível de lisina avaliado poderia estar relacionado a um gasto extra de energia para o catabolismo do excesso de lisina. Henry \& Seve (1993) atribuíram ao gasto de energia para catabolizar o excesso de aminoácidos a piora na conversão alimentar verificada nos níveis inadequados de lisina.

Os níveis de lisina na ração influenciaram $(\mathrm{P} \leq 0,05)$ de forma quadrática o rendimento de carcaça dos suínos, que aumentou até o nível estimado de $0,89 \%$ de lisina digestível (Tabela 3; Figura 3), correspondente a um consumo diário de lisina estimado de 17,28 g/dia. Resultados divergentes foram observados por Haese et al. (2011), que avaliaram níveis de lisina digestível entre 0,87 e 1,26\% para suínos machos castrados dos 60 aos 100 dias de idade e não verificaram efeito significativo dos níveis de lisina sobre o rendimento de carcaça.

Foi observado efeito $(\mathrm{P}=0,062)$ quadrático dos níveis de lisina digestível sobre a quantidade de carne na carcaça, que aumentou até o nível estimado de 0,90\% de lisina

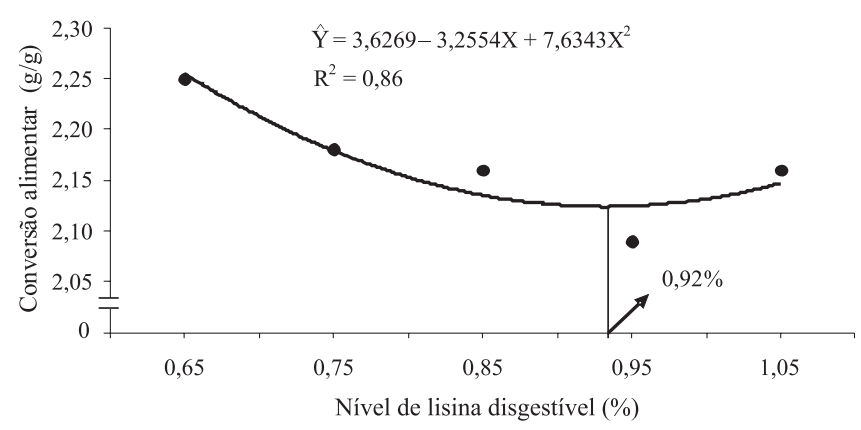

Figura 2 - Efeito do nível de lisina sobre a conversão alimentar de suínos machos castrados dos 60 aos 100 dias de idade. digestível (Tabela 3; Figura 4), correspondente a um consumo diário de lisina estimado de 17,27 g/dia. De forma semelhante, Abreu et al. (2007) verificaram efeito linear dos níveis de lisina digestível sobre a deposição de proteína na carcaça dos animais. Entretanto, Haese et al. (2011) não observaram efeito dos níveis de lisina digestível sobre a quantidade de carne magra na carcaça.

Quando a energia da ração não é fator limitante, suínos respondem a aumentos dos níveis de lisina da ração até o ponto máximo de deposição de carne na carcaça, que é determinado pelo potencial genético. Neste estudo, constatou-se redução de 6,1\% no valor absoluto na deposição de carne na carcaça quando se elevou o consumo de lisina digestível de 17,52 para 20,43 g/dia, mesmo com o consumo de energia pelos animais mantendo-se relativamente

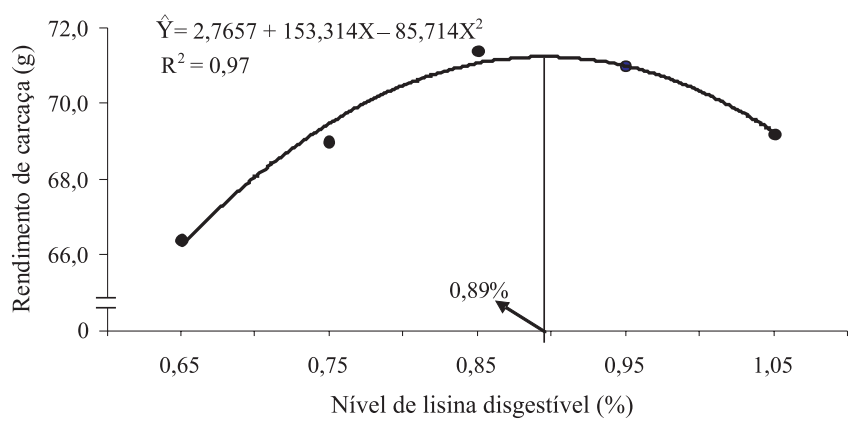

Figura 3 - Efeito do nível de lisina sobre o rendimento de carcaça de suínos machos castrados dos 60 aos 100 dias de idade.

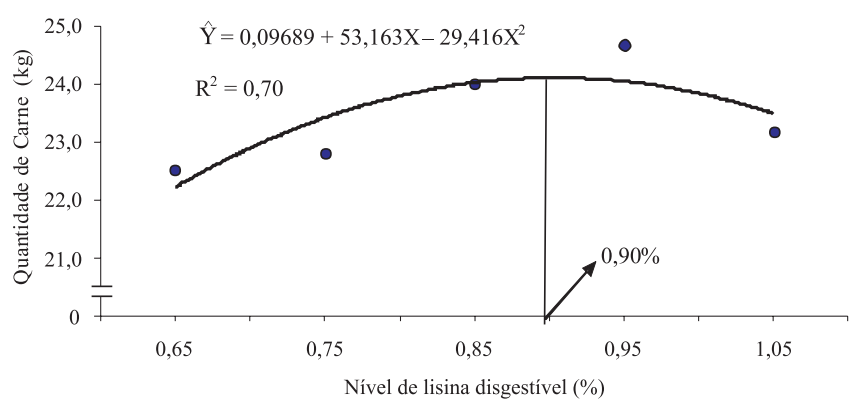

Figura 4 - Efeito dos níveis de lisina sobre a quantidade de carne magra na carcaça de suínos machos castrados dos 60 aos 100 dias de idade.

Tabela 3 - Características de carcaça de suínos machos castrados recebendo diferentes níveis de lisina digestível na ração na fase dos 60 aos 100 dias de idade

\begin{tabular}{lcccccc}
\hline Parâmetro & \multicolumn{3}{c}{ Nível de lisina digestível (\%) } & \multicolumn{2}{c}{ CV (\%) } \\
\cline { 2 - 5 } & 0,65 & 0,75 & 0,85 & 0,95 & 1,05 \\
\hline Rendimento de carcaça (\%) & 66,40 & 69,00 & 71,60 & 71,00 & 69,20 \\
Quantidade de carne (kg) $^{2}$ & 22,53 & 22,81 & 24,02 & 24,68 & 23,18 \\
Espessura de toucinho (mm) & 11,12 & 10,92 & 9,20 & 12,36 & 11,56 & 13,83 \\
\hline
\end{tabular}

1,2 Efeito quadrático $(\mathrm{P} \leq 0,05)$ e $(\mathrm{P}=0,062)$, respectivamente. 
constante entre os tratamentos. Com esses resultados pode-se deduzir que o ponto estimado para a máxima deposição de carne na carcaça de suínos machos castrados utilizados neste trabalho foi de $0,90 \%$ de lisina digestível, valor correspondente a um consumo de 17,52 g/dia de lisina digestível.

Neste estudo, o nível de lisina digestível que proporcionou os melhores resultados de deposição de carne $(0,90 \%)$ coincide com aquele que resultou em melhor conversão alimentar (0,92\%), confirmando a proposição de De Lange et al. (2001) de que o ponto de máxima deposição de proteína na carcaça é aquele no qual o animal atinge máxima eficiência alimentar.

Associando os resultados de deposição de carne na carcaça aos de ganho de peso diário, pode-se inferir que o aumento quadrático do ganho de peso diário ocorreu em razão do aumento quadrático na deposição de carne na carcaça.

Os níveis de lisina digestível estimados neste estudo, de 0,$96 ; 0,92$ e $0,90 \%$, para os melhores resultados de ganho de peso diário, conversão alimentar e deposição de carne na carcaça, respectivamente, foram superiores àquele preconizado pelo NRC (1998), de 0,82\%, para suínos de alto potencial genético na fase dos 20 aos $50 \mathrm{~kg}$. Entretanto, foram inferiores aos de 1,028\% preconizados por Rostagno et al. (2005) para suínos machos castrados dos 30 aos $50 \mathrm{~kg}$ de alto potencial genético com desempenho superior e de 1,10\% obtidos por Abreu et al. (2007) para suínos machos castrados dos 30 aos $60 \mathrm{~kg}$. Essa variação entre os resultados pode ser explicada, em parte, pelo potencial genético para deposição de carne na carcaça e pelo sexo dos animais.

Não foi observado efeito $(\mathrm{P} \geq 0,10)$ dos tratamentos sobre a espessura de toucinho dos animais. De forma semelhante, Haese et al. (2011) não observaram efeito dos níveis de lisina sobre a espessura de toucinho e Abreu et al. (2007) não constataram efeito dos níveis de lisina sobre a porcentagem de gordura e a taxa de deposição de gordura na carcaça dos suínos machos castrados. Por outro lado, Fontes et al. (2005) verificaram redução de forma quadrática na porcentagem de gordura na carcaça de leitoas dos 30 aos $60 \mathrm{~kg}$.

Verificou-se para essa variável uma incoerência nos resultados, pois, mesmo não ocorrendo diferenças significativas, houve aumento de $25,57 \%$ em valor absoluto na espessura de toucinho quando se elevou o nível de lisina de 0,85 para $0,95 \%$. Como houve aumento na quantidade de carne entre os níveis 0,85 e $0,95 \%$ de lisina e o consumo de energia digestível não variou entre os animais nos tratamentos, esperava-se redução na espessura de toucinho, em função do maior gasto energético para deposição de carne magra. Considerando-se ainda que a máxima eficiência alimentar é atingida no ponto em que o animal atinge seu potencial para deposição de proteína, esperava-se que menor quantidade de energia da ração estivesse disponível para deposição de gordura na carcaça.

\section{Conclusões}

Os níveis de 0,96 e 0,92\% de lisina digestível na ração, correspondentes, respectivamente, ao consumo de lisina digestível de 18,69 e 17,91 g/dia, proporcionam os melhores resultados de ganho de peso e conversão alimentar, enquanto os níveis de 0,89 e $0,90 \%$, correspondentes ao consumo de lisina digestível de 17,28 e 17,52 g/dia, promovem os melhores resultados de rendimento de carcaça e quantidade de carne magra em suínos machos castrados de alto potencial genético dos 60 aos 100 dias de idade.

\section{Agradecimentos}

À Perdigão S.A., pelo financiamento do projeto e apoio na realização dos trabalhos de campo; e à FESURV, por disponibilizar a estrutura física para a realização dos trabalhos de campo.

\section{Referências}

ABREU, M.L.T.; DONZELE, J.L.; OLIVEIRA, R.F.M. et al. Níveis de lisina digestível em rações, utilizando-se o conceito de proteína ideal, para suínos machos castrados de alto potencial genético, dos 30 aos $60 \mathrm{~kg}$. Revista Brasileira de Zootecnia, v.36, p.62-67, 2007.

AROUCA, C.L.C.; FONTES, D.O.; FERREIRA, W.M. et al. Exigências de lisina, com base no conceito de proteína ideal, para suínos machos castrados, de 95 a 122 kg, selecionados para deposição de carne magra. Arquivos Brasileiros de Medicina Veterinária e Zootecnia, v.56, n.6, p.773-781, 2004.

COFFEY, R.D.; PARKER, G.R.; LAURENT, K.M. Feeding growingfinishing pigs to maximize lean grow rate. University of Kentucky. College of Agriculture, 2000. Disponível em: <http://www.animalgenome.org/edu/PIH/prod_grow_finish.pdf > Acesso em: 14 maio 2007.

DE LANGE, C.F.M.; BIRKETT, S.H.; MOREL, P.C.H. Protein, fat, and bone tissue growth in swine. In: LEWIS, A.J; SOUTHERN, L.L. (Eds.) Swine nutrition. Florida: CRC Press LLC, 2001. Chapter 4, p.65-81.

D’MELLO, J.P.F. Amino acid supplementation of cereal-based diets for non-ruminants. Animal Feed Science and Technology, v.45, p.1-18, 1993.

DONZELE, J.L.; FREITAS, R.T.F.; OLIVEIRA, R.F.M. et al. Níveis de lisina para leitoas de 30 a $60 \mathrm{~kg}$ de peso vivo. Revista Brasileira de Zootecnia, v.24, p.967-973, 1994.

EDMONDS, M.S.; BAKER,DH. Amino acid excesses for young pigs: effects of methionine, tryptophan, threonine or leucine. Journal of Animal Science, v.64, p.1664-1671, 1987.

FRIESEN, K.G.; NELSSEN, J.L.; GOODBAND, R.D. et al. Influence of dietary lysine on growth and carcass composition of high- 
lean growth gilts fed from 34 to 72 kilograms. Journal of Animal Science, v.72, p.1761-1770, 1994.

FONTES, D.O.; DONZELE, J.L.; OLIVEIRA, R.F.M. et al. Níveis de lisina para leitoas selecionadas geneticamente para deposição de carne magra na carcaça, dos 30 aos $60 \mathrm{~kg}$. Revista Brasileira de Zootecnia, v.34, p.81-89, 2005.

HAESE, D.; DONZELE, J.L.; OLIVEIRA, R.F.M. et al. Digestible lysine for barrows of genetic lines selected for meat deposition from 60 to 100 days of age. Revista Brasileira de Zootecnia, v.40, n.9, p.1941-1946, 2011.

HENRY, Y.; SÉVE, B. Feed intake and dietary amino acid balance in growing pigs with special reference to lysine, tryptophan and threonine. Pig News and Information, v.14, n.1, p.35-43, 1993.

KESSLER, A.M. Exigências nutricionais para máximo rendimento de carne em suínos. In: SIMPÓSIO SOBRE RENDIMENTO E QUALIDADE DA CARNE SUÍNA, 1998, Concórdia. Anais... Concórdia, 1998. p.18-25.

NATIONAL RESEARCH COUNCIL - NRC. Comittee Animal Nutrition. Nutrient requirements of swine. 10.ed. Washingorn: National Academic Press, 1998. 189p.

PUPA, J.M.R.; ORLANDO, U.A.D.; HANNAS, M.I. et al. Nutritional levels used in Brazilian swine diets. In: SIMPÓSIO
INTERNACIONAL SOBRE EXIGÊNCIAS NUTRICIONAIS DE AVES E SUÍNOS, 2., 2005, Viçosa, MG. Anais... Viçosa, MG: UFV, Imprensa Universitária, 2005. p.235-251

QUINIOU, N.; NOBLET, J.; DOURMAD, J.Y. et al. Influence of energy supply on growth characteristics in pigs and consequences for growth modeling. Livestock Production Science, v.60, p.317-328, 1999.

ROSTAGNO, H.S.; ALBINO, L.F.T.; DONZELE, J.L. et al. Tabelas brasileiras para aves e suínos: composição de alimentos e exigências nutricionais. Viçosa, MG: UFV, 2005. 186p.

SANTOS, F.A.; DONZELE, J.L.; SILVA, F.C.O. et al. Níveis de lisina digestível para suínos machos castrados de alto potencial genético dos 95 aos $125 \mathrm{~kg}$. Revista Brasileira de Zootecnia, v.40, n.5, p.1038-1044, 2011.

SOUZA, A.M. Exigências nutricionais de lisina para suínos mestiços, de 15 a 95 kg de peso. 1997. 81f. Dissertação (Mestrado em Zootecnia) - Universidade Federal de Viçosa, Viçosa, MG.

WARNANTS, N.; VAN OECKEL, M.J.; PAEPE, M. Response of growing pigs to different levels of ileal standardized digestible lysine using diets balanced in threonine, methionine and tryptophan. Livestock Production Science, v.82, p.201-209, 2003. 